\title{
Article
}

\section{KMapper: A Field Geological Survey System}

\author{
Young-Kwang Yeon
}

check for

updates

Citation: Yeon, Y.-K. KMapper: A Field Geological Survey System. ISPRS Int. J. Geo-Inf. 2021, 10, 405. https://doi.org/10.3390/ijgi10060405

Academic Editors: Wolfgang Kainz and Mauro De Donatis

Received: 10 May 2021

Accepted: 10 June 2021

Published: 12 June 2021

Publisher's Note: MDPI stays neutral with regard to jurisdictional claims in published maps and institutional affiliations.

Copyright: (C) 2021 by the author. Licensee MDPI, Basel, Switzerland. This article is an open access article distributed under the terms and conditions of the Creative Commons Attribution (CC BY) license (https:/ / creativecommons.org/licenses/by/ $4.0 /)$.
Geoscience Platform Research Division, Korea Institute of Geoscience and Mineral Resources Resources (KIGAM), 124, Gwahak-ro, Yuseong-gu, Daejeon 34132, Korea; ykyeon@kigam.re.kr

\begin{abstract}
The computing power of smart mobile devices has evolved as much as the power of desktop personal computers (PCs). Accordingly, a field geological survey system capable of utilizing the performance of smart devices is needed. Thus, the objective of this paper is to introduce a system with functions to take advantage of the performance of smart devices while meeting the various requirements of a geological survey. The system integrates geographic information system functions and smart sensors to execute field geological surveys effectively and can express various collections on a map. It also includes a map editing function that allows users to edit geological boundaries and areas on a map from the touch-based interface of a smart device. The records collected can be exported for editing of the geological map on a desktop PC. The developed app can replace traditional recording media used in field geological surveying and exploration work. It can be used to acquire location-referenced measurements with smart sensors, making field work more effective.
\end{abstract}

Keywords: mobile GIS; information and data capturing; database; smart sensor; outcrop survey

\section{Introduction}

Traditional field geological surveys include searching for geological outcrops, surveying various geological phenomena, and describing the findings in media such as a field notebook and maps [1,2]. The information recorded during a field geological survey is interpreted through analysis of specimens, and a geological map is constructed, which involves repeated retrievals and refinements of collected records. Therefore, to efficiently utilize the information recorded during a field geological survey, it is advantageous to record the information in digital form.

Various efforts have been made to develop a field geological survey system for the purposes of collecting and managing survey data in the form of digital information. Existing systems have diversified from the operating system (OS) perspective into highly portable OS environments, such as Windows CE [3,4], which is increasingly being used in portable devices in Microsoft Windows [5-10]. More recently, the expansion of smart mobile devices has resulted in the introduction of field geological survey systems that can operate on Android and iOS systems [11-14]. This trend toward mobile OS environments is apparent in the OS market share. According to statistics from StatCounter [15], a web traffic analysis site, until 2017, most of the market share was held by OSs for PCs, but the market shares for smart mobile OSs and PC OSs have become similar since 2017 (Figure 1). As suggested by these statistics, smart mobile devices represent an axis of major computing devices, and an ecosystem of utilization has been established. 


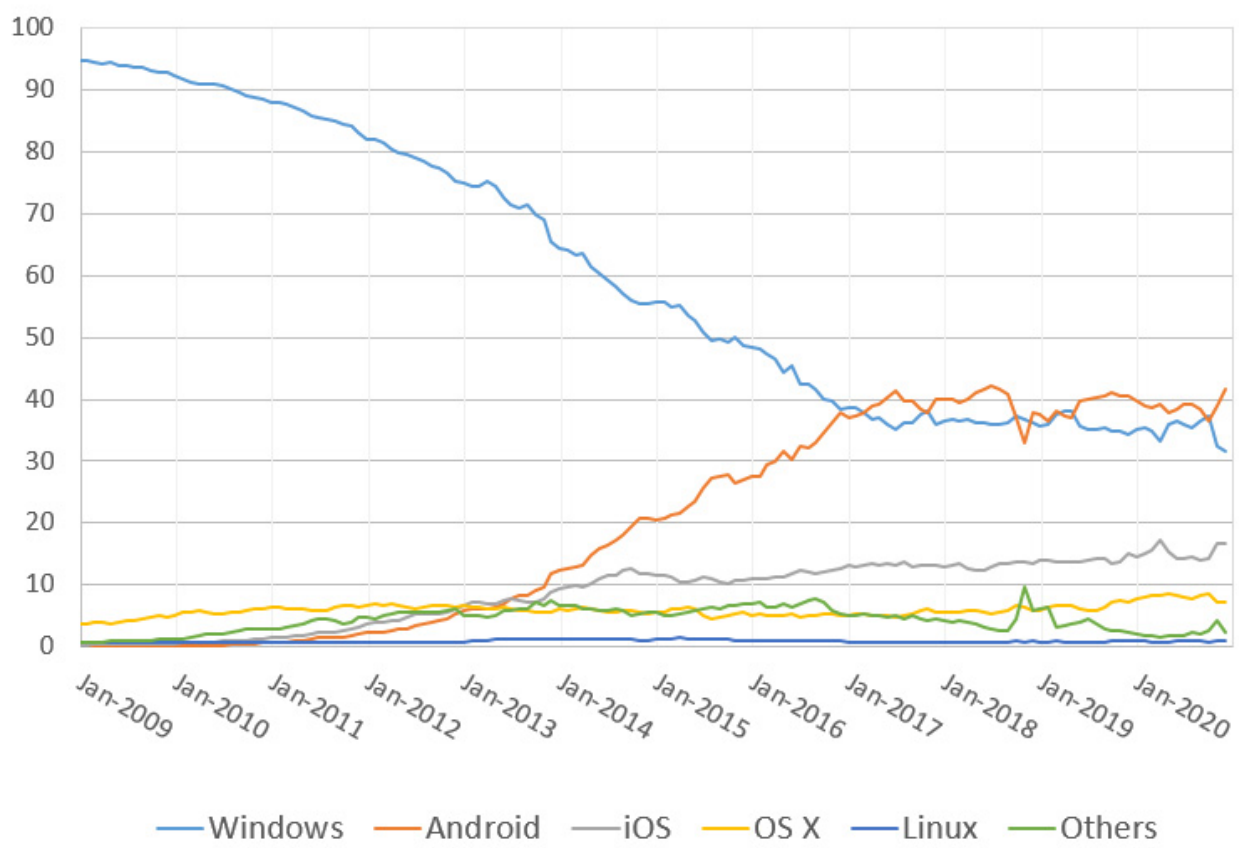

Figure 1. Market share of operating systems worldwide from January 2009 to January 2021 (the graph was developed using data from StatCounter Global Stats [15]).

The initial smart mobile devices provided limited functionality to facilitate simple tasks such as communication, photography, electronic calculating, using dictionaries, and writing memos. Since that time, as computational capabilities have expanded [16], smart mobile devices have diversified in usability to include games requiring high performance, large-capacity document capabilities, and graphic editing. An additional reason for the expanded use of smart mobile devices is the implementation of built-in sensors. Unlike conventional computing devices, smartphones have various types of sensors, such as for geomagnetic measurement, posture measurement, and imaging. Smartphone sensors [17-19] can be used to measure various states or collect information because they can detect environmental changes and movements, positioning, voice, and images, as shown in Table 1. Thus, smart mobile devices with various sensors can be used as an efficient tool for field geological surveys.

Table 1. Sensor classification by type.

\begin{tabular}{cc}
\hline Type & Sensors (Components) \\
\hline Motion detection & Acceleration sensor, gyro sensor \\
Environment sensing & Gravity sensor, geomagnetic sensor (compass) \\
Positioning system & GPS, WiFi sensor, 4G \\
Visual sensing & Camera image sensor \\
\hline
\end{tabular}

Smart mobile devices can meet advanced requirements beyond the role of the typical recording media used in conventional geological surveys. For example, they can replace field slips and field notebooks, and recording media used in traditional geological surveys, as well as hardware such as compasses, clinometers, and cameras. They can also include data on a map using geometry for geological features identified in the field and can effectively retrieve and modify collected records using database (DB) management techniques.

However, the development of field geological survey systems on smart mobile devices is a challenging task because they are implemented in an environment more restrictive than a desktop [20-22]. Smart devices using touch-based interfaces cannot use the traditional methods for operating desktop PCs, such as precise mouse operation and right-click event 
calls, and must also provide menus and operating environments with limited screen sizes [23-25]. In addition, system implementation on smart devices has the challenges of needing to combine with DB management technology to store and retrieve collected data, geographic information system (GIS) technology to represent or describe geological features, smart metering sensor control technology, and image processing technology [26].

This paper reviews the requirements for field geological surveys considering the functions of smart mobile devices and presents KMapper, a field geological survey system developed through these functions. In the analysis of requirements, detailed tasks of the field geological survey process are defined as elements for implementation on smart digital devices. Then, a new system is provided to users by addressing the various challenges of implementing field geological survey functions on smart devices. Various measurement tools used in geological surveys are replaced by sensors on a smartphone.

\section{Materials and Methods}

\subsection{Analysis of Requirements}

To replace previously used recording media, a field geological survey system must be designed so that it can record digital data beginning in the survey stage with digital tools useful during the survey process. When conducting a traditional field geological survey, the locations of localities, photographs, measured geological structures, collected rock specimens, directly observed outcrop areas, etc., are marked on a field slip, and detailed descriptions are written in a field notebook. The information written into these two recording media includes identification numbers for cross-referencing. For example, the rock and fossil specimens collected may be cross-referenced with the contents of the field notebook and the locations listed in field slips. Rock specimens are identified through analysis processes to determine rock type and origin, and the results establish relationships between rock layers. The geological map is completed by comprehensively interpreting the specimen analysis results along with the contents of the field notebook and field slips.

System requirements for using digital recording media can be derived by dividing the data recorded in the geological survey process into data of the preliminary survey phase, field survey phase, and review and management phase (Table 2).

\subsection{System Data Architecture}

Data collected during geological surveys are structured by defining relationships (Figure 2) and packaged on a project basis. The information in the package consists of locality data, photographs, sketched content on the photographs, structural measurements, samples, and memo data. Rock units associated with each locality must be cross-referenced with structures and specimens. The survey data must be structured in conjunction with the locality but have a weak relationship with it. That is, individual survey data should have a reference relationship with locality information as independent survey data rather than a subordinate relationship with a particular locality. Geological features represented by polygons among the geometry elements on the drawing may be linked to rock units. In the correspondence between digital and traditional recording media, geometry elements on the map correspond to field slips, and detailed records correspond to the field notebook. The descriptive content collected in the digital geological survey system is collected in a spreadsheet, and the geometry elements depicted on the map are converted into a GIS layer. 
Table 2. Requirements of each system usage step.

\begin{tabular}{|c|c|}
\hline Step & Uses \\
\hline $\begin{array}{c}\text { Preliminary } \\
\text { survey }\end{array}$ & $\begin{array}{l}\text { 1. Prepare offline maps (satellite maps, shaded relief maps, and } \\
\text { others) } \\
\text { 2. Literature survey }\end{array}$ \\
\hline Field survey & $\begin{array}{l}\text { 1. Field survey } \\
\text { - Identify geological type locality } \\
\text { - Temporarily define rock units } \\
\text { - Take photographs or sketch an outcrop } \\
\text { - Measure geologic structures } \\
\text { - Collect specimens (rocks and fossils) } \\
\text { - Describe geological features with text and drawings } \\
\text { 2. Use of GIS content } \\
\text { - Check current location } \\
\text { - Measure distance and area } \\
\text { - Online geologic maps } \\
\text { - Online and offline topographic maps } \\
\text { 3. Map editing } \\
\text { - Draw points, lines, and polygons } \\
\text { - Modify geometry features }\end{array}$ \\
\hline Data review and management & $\begin{array}{l}\text { 1. Review collected records } \\
\text { - Refine rock units } \\
\text { - Check records and their locations } \\
\text { - Modify or add comments on a sketch } \\
\text { 2. Backup and export data } \\
\text { - Export survey records as a spreadsheet } \\
\text { - Export location data as georeferenced geometry data }\end{array}$ \\
\hline
\end{tabular}

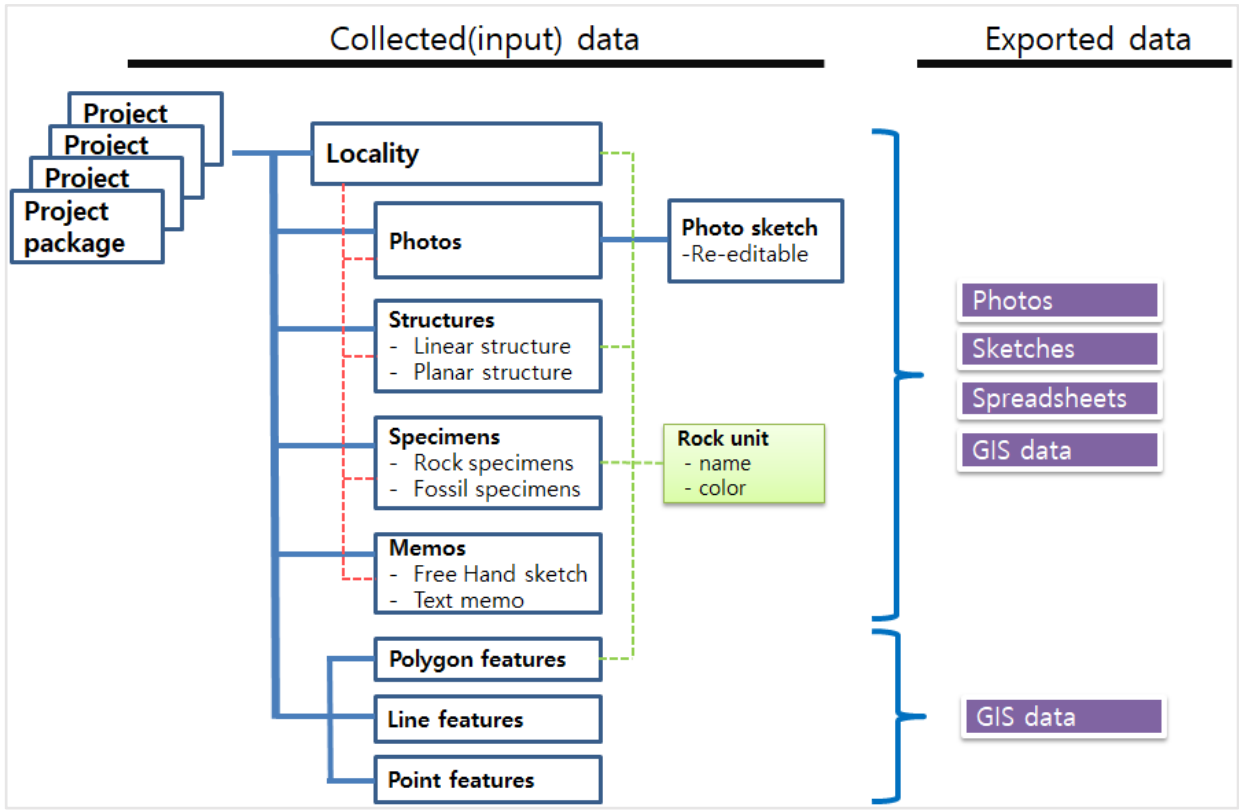

Figure 2. Data configuration and relationships between collected and exported data.

Additionally, sensors integrated into smart devices can replace equipment used in traditional geological surveys. Sensors that can be used in smart devices, as shown in Table 3, include sensors for acquiring photographs, locations, gravity measurements, geological structures, and azimuth measurements, which are typical operations performed in the traditional geological survey process. 
Table 3. Sensors used in KMapper.

\begin{tabular}{cc}
\hline Task & Sensors \\
\hline Acquiring images & Camera image sensor \\
Positioning & GPS, WiFi sensor, 4G \\
Gravity measurement & Gravity sensor \\
Geologic structures & Acceleration sensor, gyro sensor \\
Bearing measurement & Geomagnetic sensor (compass) \\
\hline
\end{tabular}

\section{Implementation Results}

KMapper (Figure 3), developed in this work, is available in Android environments (Table 4). It is more useful if a pen is included with hardware requirements to edit maps and make sketch notes. In addition, sensors necessary for measuring location, geomagnetic data, azimuth, and geological structures are required for the measurement processes. The tools included in the system menu consist of project, outcrop survey, map editing, data management, information, and system setup tools. The project tool includes menus to create, delete, and update projects. The system setup tool consists of menus associated with location input methods, other menus, and map control methods.

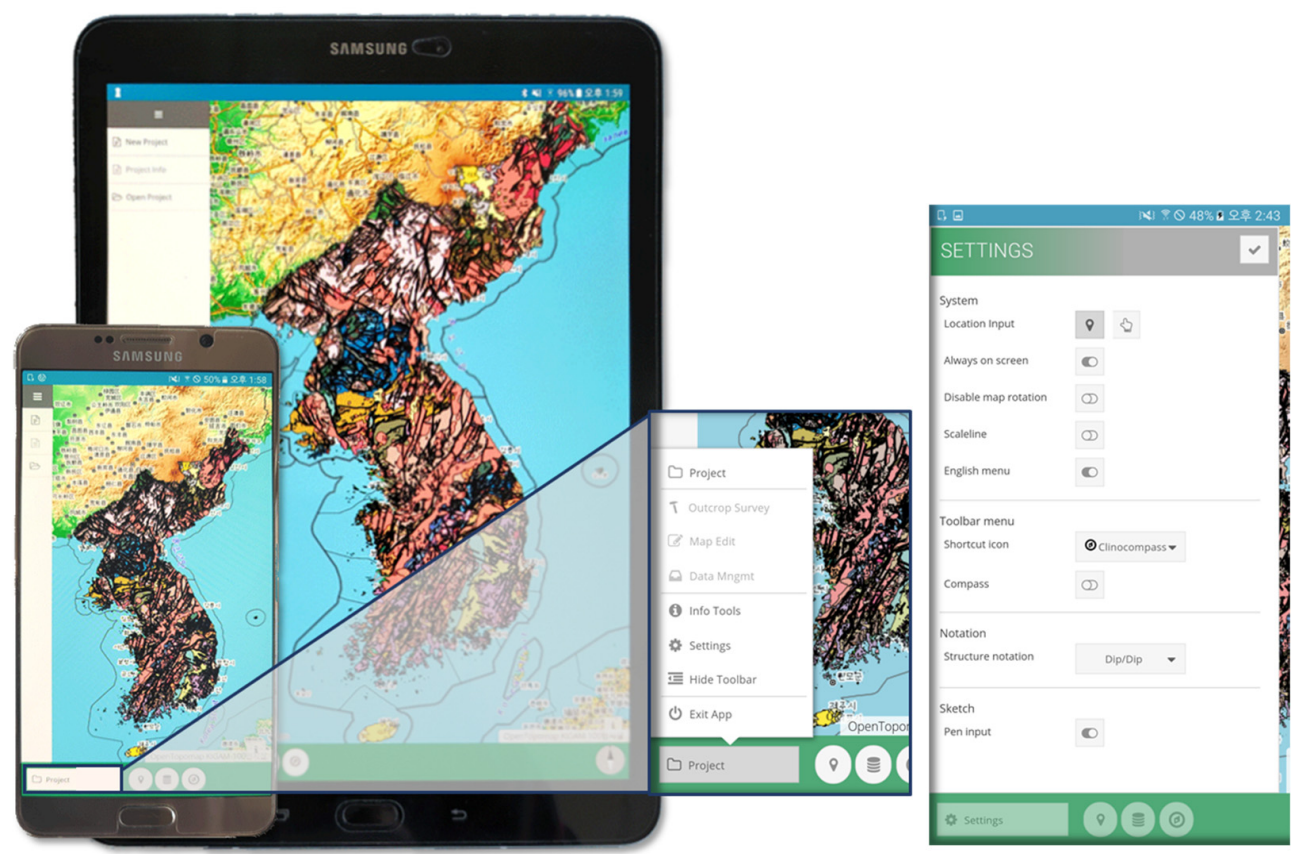

Figure 3. Screenshots of the system: app launch screen, tool menu, and system settings panel.

Table 4. Tested device specifications.

\begin{tabular}{cc}
\hline Title & Content \\
\hline OS & Android 5.0 or above \\
Hardare & Smartphone and pad (pen recommended) \\
Tested devices & Smartphone (Samsung Galaxy Note 5, Note 10, and Note 20) \\
Current app version & Smartpad (Samsung Galaxy Tab Active 3 and S3) \\
Intra-institutional release
\end{tabular}

\subsection{Outcrop Survey Tool}

The outcrop survey tool consists of input menus for locality information, photographs, geological structures, specimens, and notes (Figure 4). The locality entered is linked to the data entered until a new locality is registered. If collected data not associated with a 
locality are to be entered, the locality designation can be disabled. Additional descriptions of photographs can be inserted by adding a mark or note to the photograph. If structural features are found in rocks, they can be measured based on the type of structure. A measurement value appropriate for a planar or linear structure and a notation can be added on the structure input screen. As an example, when the dip direction and dip angle are 096 and 13, respectively, the values are interchangeable with the values of N8E and 5SE in the quadrant notation. Measured values can also be entered from the implemented compass-clinometer. If rock or fossil specimens are acquired, the corresponding symbol type can be entered on the map. Notes can also be added to the map as either text or a sketch. Online and offline maps are available during the field survey process, and current location information can be obtained using a network or the Global Positioning System (GPS). The location of the survey data is obtained directly from the smart device or entered via touch input on the map shown on the screen, depending on the system settings. The survey data entered are displayed on the map by an icon symbol depending on their type, and the location can be changed by moving the icon or by entering the latitude and longitude coordinates.

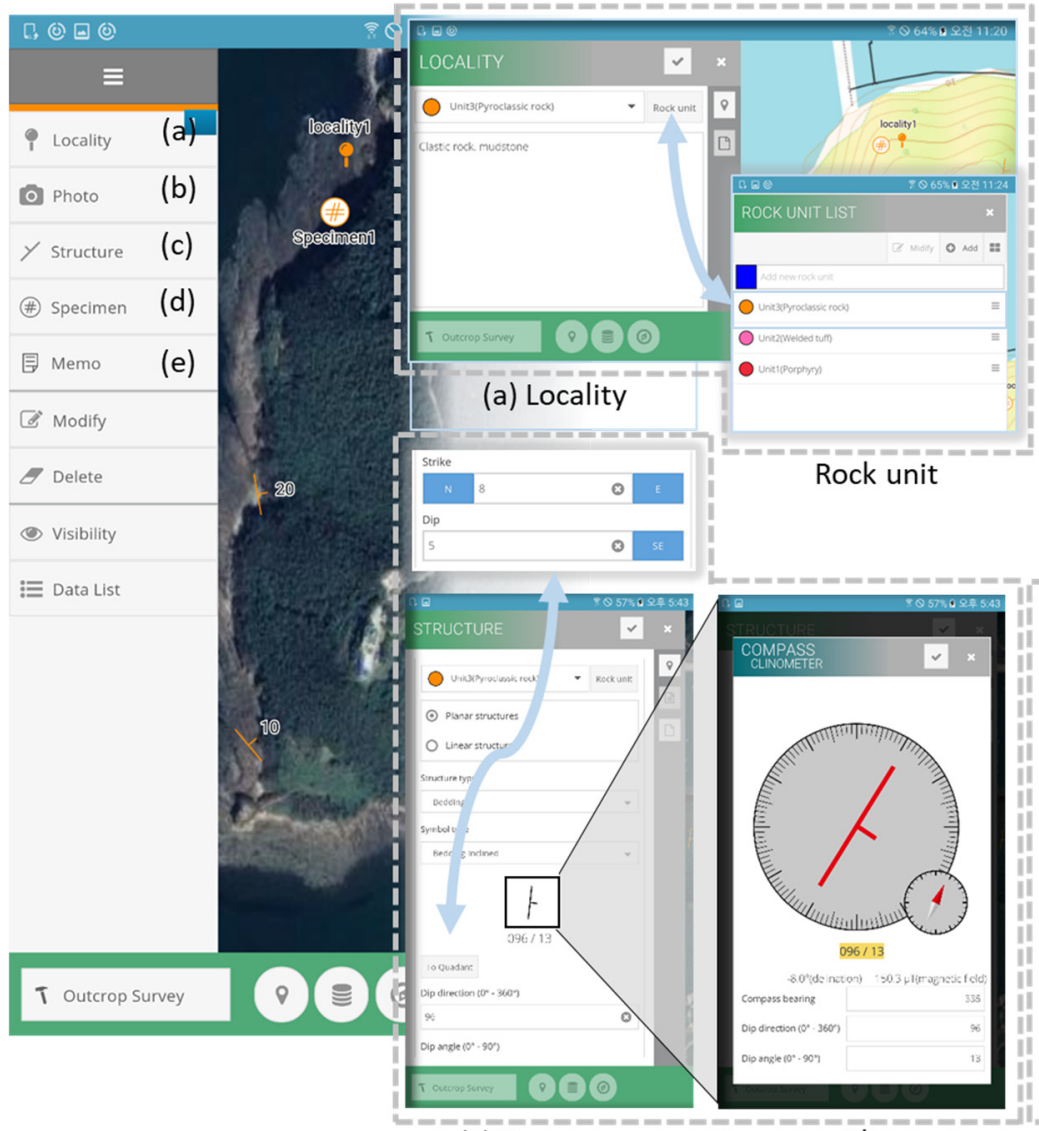

(c) Structure

Compass-Clinometer
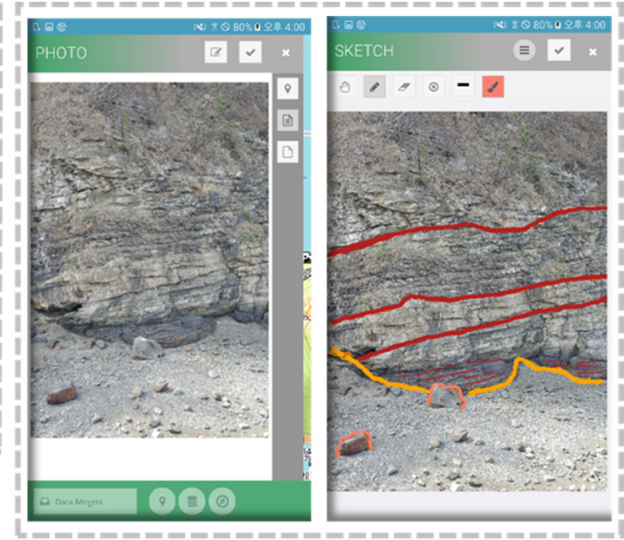

(b) Photo \& sketch

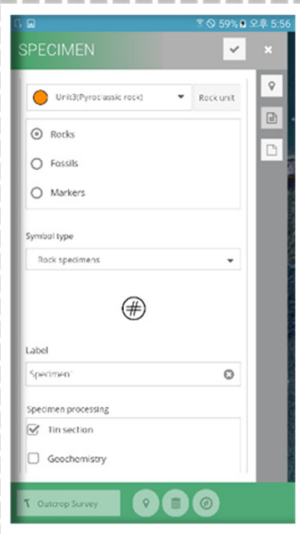

(d) Specimen

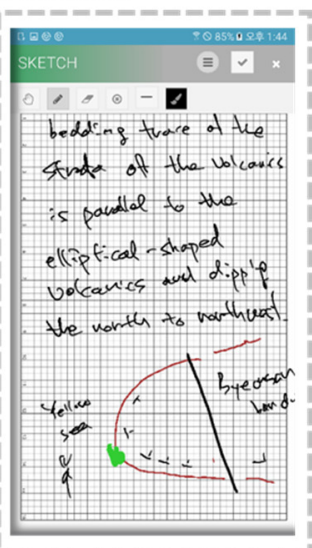

(e) Memo

Figure 4. Outcrop survey tool and functions: (a) locality input panel and associated rock units, (b) photograph acquisition and sketching, (c) structure input panel and associated measurement tool (dip/dip $\leftrightarrow$ quadrant switching of structural notation), (d) specimen input panel, and (e) handwritten memo and sketch panel.

\subsection{Map Editing Tool}

The map editing tool provides functions for describing geological features on a map using geometry elements (Figure 5). Points, lines, and polygons can be used with inserted labels and symbols to characterize a particular location, describe a rock boundary or surface fault line, or identify areas. Editing functions include transforming the geometry between 
lines and polygons, cutting lines, and connecting lines. Various representations of lines, such as colors and patterns, can be used. Polygon areas can be associated with a rock unit, and the area can be represented by the color defining the rock unit.

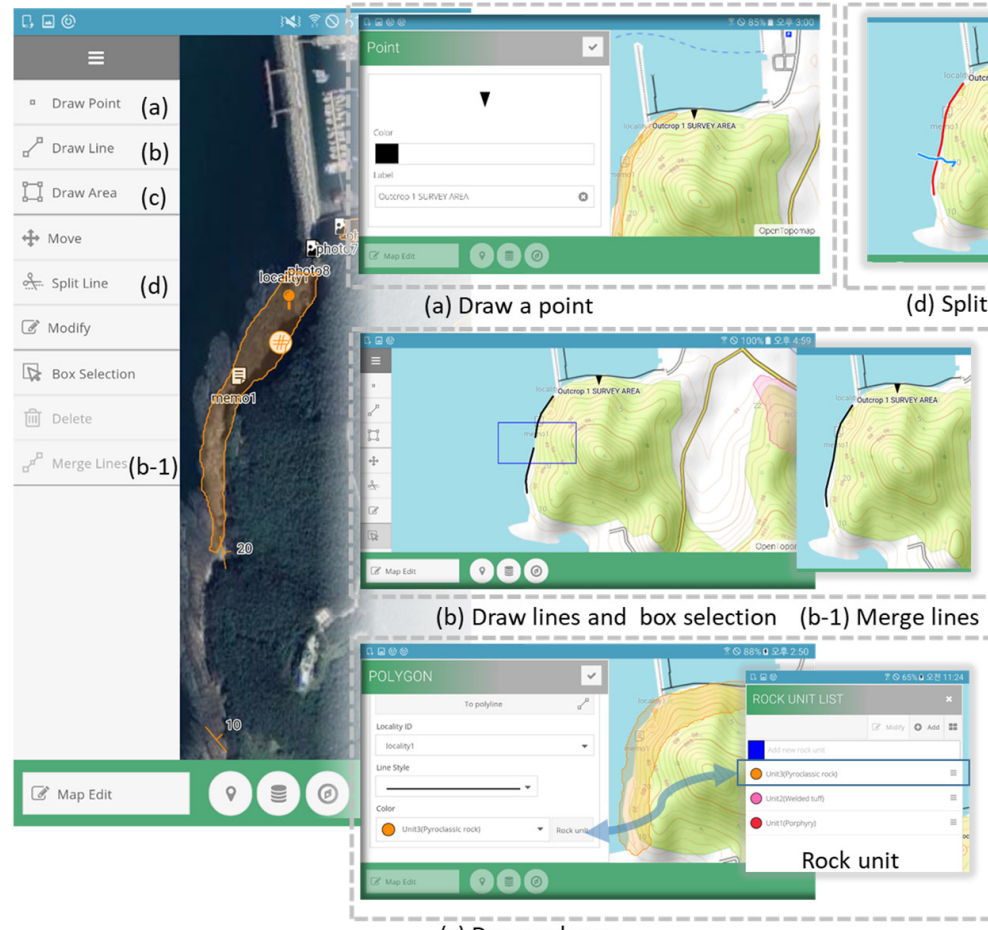

(c) Draw polygon

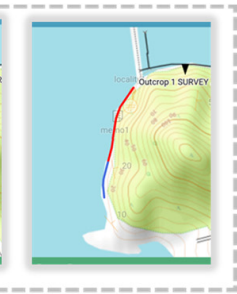

Split a line and change color

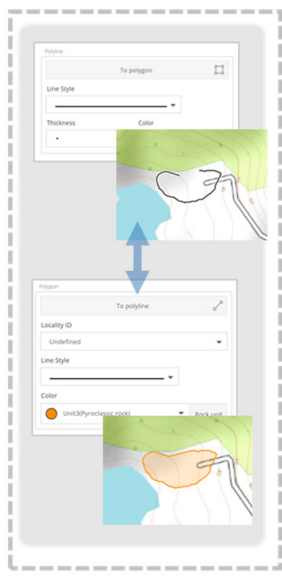

Polyline to polygon

Figure 5. Map editing tools and functions: (a) point creation for label entry, (b) line drawing and box selection with line merge (two to one), (c) polygon drawing panel and associated rock units, and (d) line splitting and color control.

\subsection{Info Tool}

The info tool includes menus for purposes such as viewing geological map properties, measuring distances and areas, and viewing the compass (Figure 6). Geological maps can be switched among scales of 1:1,000,000, 1:250,000, and 1:50,000 depending on the zoom level, and maps serviced by the Web Map Service protocol can be viewed according to the properties of the features of the displayed map. In addition, measurement work can be carried out using the compass, clinometer, and distance and area calculation tools.

\subsection{Data Management Tool}

The data recorded through the outcrop survey menu are represented by a list of each type of data. Each list includes the locality, photographs, structures, samples, and notes. List items are identified by their location in conjunction with the base map, and detailed content can be viewed or modified. Items in the list can be rearranged by locality, input date, and rock unit. Records entered using the outcrop survey tool are converted to Excel and GeoJSON formats depending on the data type, and records recorded by the map editing tool are exported to a GeoJSON file. The exported files can be used for completion of a geological map in a desktop environment or backed up for long-term storage (Figure 7). 

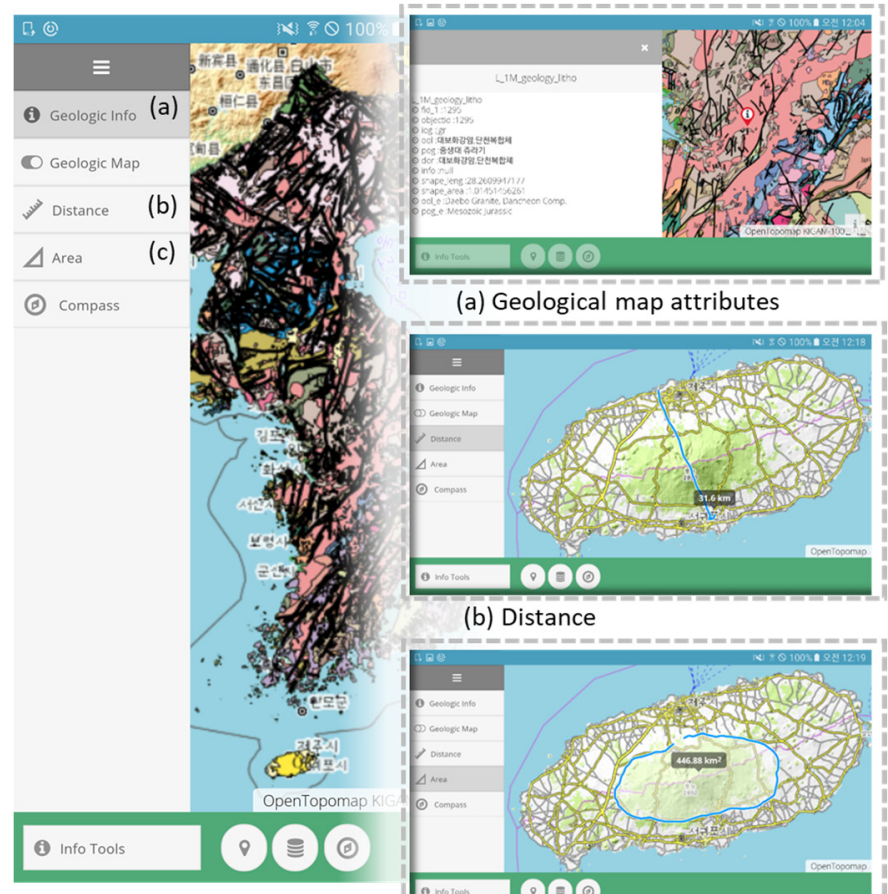

(a) Geological map attributes

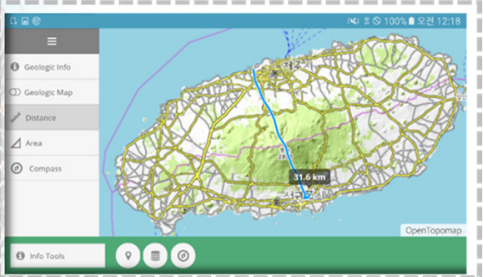

(b) Distance

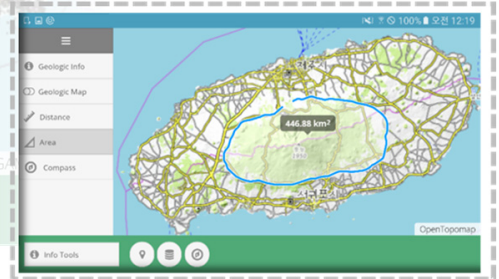

(c) Area

Figure 6. Info tool: (a) geological map attributes, (b) distance measurement, and (c) area determination.

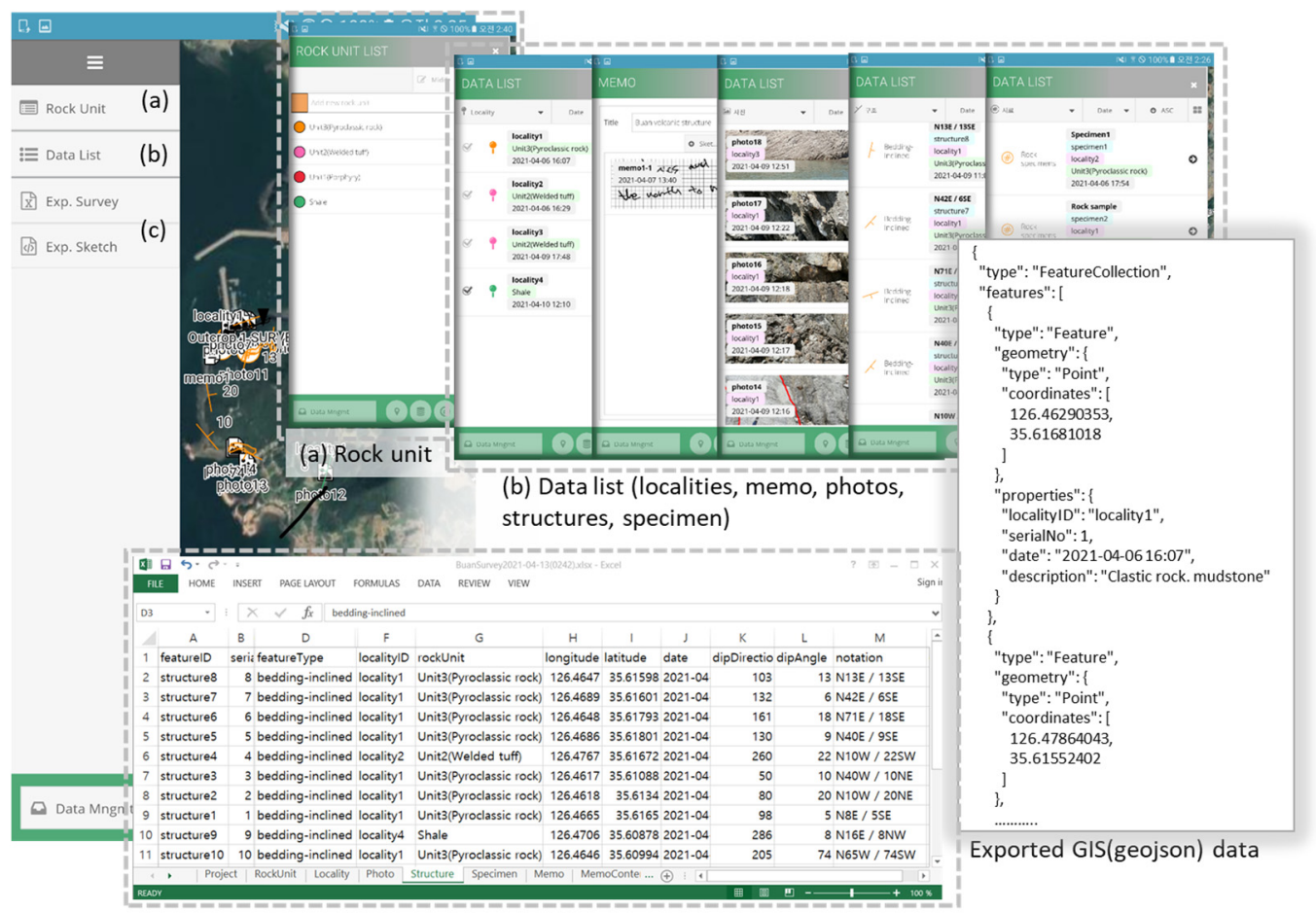

(c) Exported spreadsheet data

Figure 7. Data management tools: (a) rock units, (b) data list, and (c) exporting results as spreadsheet or GIS data.

Additional implemented technologies are applied with DB management, GIS, and smart sensor technologies according to the system utilization stage (Table 5). In the preinvestigation phase, the work of collecting and entering prepared data is performed, and DB management technology, GIS, and graphic technology elements can be implemented accordingly. In the field survey stage, when the location and structure of observed geologi- 
cal features are measured or descriptive content is recorded in photographs or memos, the necessary DB, sensor measurement, GIS, and graphic processing techniques are used. In the data review and management process, DB, GIS, and graphics processing techniques are used to retrieve and modify previously collected data.

Table 5. Technical elements of implemented functions of the field geological survey system.

\begin{tabular}{|c|c|c|c|c|c|}
\hline & Functional element & DB & Sensor & GIS & Graphics \\
\hline $\begin{array}{l}\text { Preliminary } \\
\text { survey }\end{array}$ & $\begin{array}{l}\text { - Create, update, and delete a } \\
\text { project } \\
\text { - Input offline maps } \\
\text { - Input known rock units }\end{array}$ & $\bigcirc$ & & $\begin{array}{l}\bigcirc \\
0\end{array}$ & \\
\hline Field survey & $\begin{array}{l}\text { - Check current location } \\
\text { - Input a new locality } \\
\text { - Take photographs and input } \\
\text { sketches } \\
\text { - Measure geologic structures } \\
\text { - Input specimens } \\
\text { - Input text memos } \\
\text { - Draw geologic features } \\
\text { - Check current location } \\
\text { - Measure distance and area } \\
\text { - Online geologic maps } \\
\text { - Online and offline maps } \\
\text { - Draw points, lines, and } \\
\text { polygons } \\
\text { - Modify geometry features }\end{array}$ & $\begin{array}{l}0 \\
0 \\
0 \\
0 \\
0\end{array}$ & $\bigcirc$ & $\begin{array}{l}0 \\
0 \\
0 \\
0 \\
0 \\
0 \\
0 \\
0 \\
0 \\
0\end{array}$ & $\begin{array}{l}0 \\
0\end{array}$ \\
\hline $\begin{array}{l}\text { Data review } \\
\text { and } \\
\text { management }\end{array}$ & $\begin{array}{l}\text { - Modify rock units } \\
\text { - Edit collected data } \\
\text { - Search collected records } \\
\text { - Export collected data }\end{array}$ & $\begin{array}{l}\bigcirc \\
0 \\
0 \\
\bigcirc\end{array}$ & & & \\
\hline
\end{tabular}

\section{Discussion}

As existing field geological survey tools, apps for geological structural measurement [11-14] and for specific purpose survey records have been introduced in the literature [27]. However, geological surveys for geological map creation collect various data, meaning system functions need to be extended to replace recording media such as field notebooks and field slips. In this study, to take this aspect into account and to implement the requirements to replace existing recording media and make smart sensors available for geological surveys, the traditional field geological survey process was divided into detailed tasks to derive the implementation requirements of the system, and these requirements were used to develop the system. The challenging aspects for the development of the smart mobile-based field geological survey system were solved as follows.

As mentioned by Novakova and Pavlis [28,29], data obtained from smart sensors can be prone to errors depending on the device and environment in which they are used. They suggested using a geological compass and a smart app together. To deal with this issue flexibly, KMapper is implemented so that users can directly input or modify measured values on smart devices by selecting the quadrant or dip/dip notation in the method of structural measurement data input. To address location accuracy problems that may arise depending on the performance of the smartphone used, the location icon entered on the map can be modified by either "drag and drop" operation or by entering longitude and latitude location values directly.

As the screen size of smart mobile devices varies, menus and operating environments should be available at a limited screen size if the screen size is small [23,24]. KMapper was developed to provide horizontal and vertical screen modes to overcome problems with 
limited screen size and allow the contents of the panel screen and the map screen to be used together.

The touch-based screen interfaces on smart mobile devices cannot use operating methods such as double clicks and right clicks traditionally used in mouse input methods [25]. These features allow only limited tasks for delicate processes such as mapping in GIS. The developed system was enabled to perform "connect" and "cut" operations on polylines with simple touch actions. A polygon can be converted easily, meaning polygons can be edited through polyline conversion (Figure 5).

\section{Conclusions}

The various data recorded in a field geological survey are revisited in the survey review processes, in which geological phenomena are interpreted to complete a geological map. For more effective interpretation of geological information and review of collected data, it is most advantageous to manage digital data from the collection stage. Digital smart devices have data processing power, portability, and integration of various sensors, meaning they can be an optimal hardware alternative for performing a field geological survey. Therefore, in this study, problems were solved by first deriving the important challenges to be addressed along with the requirements of a field geological survey that fit the various functions and performances of smart mobile devices. As a result, a digital geological mapping system, KMapper, was developed by combining screen design, touch interface drawing and editing, DB, sensor utilization, GIS, and graphic processing technologies capable of being utilized with various screen sizes.

KMapper is available on the Android OS and is designed to be used with various screen sizes such as those of tablets and smartphones. If a pen is available, sketches and notes can be added efficiently, and the location input method can be selected as GPS or screen touch input depending on the environment of use. Various record data, such as photographs, geological structures, specimens, and memos, based on the location can be collected during a geological survey. The map editing function can illustrate geological features using points, lines, and polygons. Specific locations can be described with labels. Geological boundaries can be expressed with various symbols and colors and can be edited easily from the touch-based interface using the "line cut" and "line connect" tools. In addition, if the boundary of an outcrop area is in the form of a region, a line can be easily converted to an area, and an outcrop area can be easily edited to a line. Furthermore, offline maps can be added, and inputs can be exported to allow work in a desktop environment.

KMapper, with these functions, can be used as a geological surveying tool for creating geological maps as well as for various exploration tasks in the field. In addition, field surveys obtained using digital devices can be used in geotourism to provide GPS locationbased services as well as in education due to the ease of obtaining quantitative data.

Funding: This research was supported by the Basic Research Project (Project No. GP2020-003) of the Korea Institute of Geoscience and Mineral Resources (KIGAM), funded by the Ministry of Science, ICT and Future Planning, Korea.

Institutional Review Board Statement: Not applicable.

Informed Consent Statement: Not applicable.

Data Availability Statement: The software from this research will be available upon request to the author.

Acknowledgments: The author would like to thank members of the KIGAM Geological Research Center for their helpful suggestions and discussions in various practical field survey experiences, and would like to thank the anonymous reviewers for their constructive comments.

Conflicts of Interest: The authors declare no conflict of interest. 


\section{References}

1. Lisle, R.J.; Brabham, P.; Barnes, J.W. Basic Geological Mapping, 5th ed.; John Wiley and Sons: Hoboken, NJ, USA, $2013 ;$ pp. 146-154.

2. Angela, L.C.; Tom, W.A.; David, A.R.; Robert, A.S. Geological Field Techniques; Coe, A.L., Ed.; John Wiley and Sons: Hoboken, NJ, USA, 2010; pp. 53-101.

3. Edmondo, G.P. Digital geologic field mapping using ArcPad. In Proceedings Digital Mapping Techniques'02-Workshop; Soller, D.R., Ed.; US Geological Survey: Salt Lake, Utah, USA, 2002; Volume 370, pp. 129-134.

4. McCaffrey, K.J.W.; Jones, R.R.; Holdsworth, R.E.; Wilson, R.W.; Clegg, P.; Imber, J.; Holliman, N.; Trinks, I. Unlocking the spatial dimension: Digital technologies and the future of geoscience fieldwork. J. Geol. Soc. 2005, 162, 927-938. [CrossRef]

5. Brown, K.D.; Sprinkel, D.A. Geologic field mapping using a rugged tablet computer. In Proceedings Digital Mapping Techniques' 07 Workshop; Soller, D.R., Ed.; US Geological Survey: Columbia, SC, USA, 2008; pp. 53-58.

6. Jordan, C.J.; Napier, B. Developing digital fieldwork technologies at the British Geological Survey. Geol. Soc. Lond. 2015, 436, 219-229. [CrossRef]

7. Struik, L.C.; Atrens, A.; Haynes, A. Hand-held computer as a field notebook and its integration with the Ontario Geological Survey's 'FIELDLOG'program. Geol. Surv. Can. Curr. Res. Part A 1991, 91, 279-284.

8. Walker, J.D.; Black, R.A. Mapping the outcrop. Geotimes 2000, 45, $28-31$.

9. Brimhall, G.H.; Vanegas, A. Removing science workflow barriers to adoption of digital geological mapping by using the GeoMapper Universal Program and visual user interface. In Proceedings Digital Mapping Techniques'01-Workshop; Soller, D.R., Ed.; US Geological Survey: Denver, CO, USA, 2001; pp. 01-223.

10. De Donatis, M.; Bruciatelli, L. MAP IT: The GIS software for field mapping with tablet pc. Comput. Geosci. 2006, 32, 673-680. [CrossRef]

11. Weng, Y.H.; Sun, F.S.; Grigsby, J.D. GeoTools: An android phone application in geology. Comput. Geosci. 2012, 44, 24-30. [CrossRef]

12. Lee, S.; Suh, J.; Park, H.D. Smart Compass-Clinometer: A smartphone application for easy and rapid geological site investigation. Comput. Geosci. 2013, 61, 32-42. [CrossRef]

13. Vaughan, A.; Collins, N.; Krus, M.; Rourke, P. Recent development of an earth science app—FieldMove Clino. In Proceedings of the EGU General Assembly Conference Abstracts, Vienna, Austria, 27 April-2 May 2014; p. 14751.

14. De Donatis, M.; Rossi, A.; Bartoccioni, L.; Cortellucci, D. Open source in field geology: A QGIS-mate Android compass. In Proceedings of the Congresso Congiunto SGI-SIMP "Geosciences for the Environment, Natural Hazards and Cultural Heritage", Catania, Italy, 12-14 September 2018; p. 114.

15. StatCounter Global Stats. Available online: https://gs.statcounter.com/os-market-share (accessed on 15 January 2021).

16. Daly, D.C.; Fujino, L.C.; Smith, K.C. Through the looking glass-The 2017 ed.: Trends in solid-state circuits from ISSCC. IEEE Solid-State Circuits Mag. 2017, 9, 12-22. [CrossRef]

17. Frank, R. Understanding Smart Sensors, 3rd ed.; Artech House: London, UK, 2013; pp. 1-15.

18. Lane, N.D.; Miluzzo, E.; Lu, H.; Peebles, D.; Choudhury, T.; Campbell, A.T. A survey of mobile phone sensing. IEEE Commun. Mag. 2010, 48, 140-150. [CrossRef]

19. Su, X.; Tong, H.; Ji, P. Activity recognition with smartphone sensors. Tsinghua Sci. Technol. 2014, 19, 235-249. [CrossRef]

20. Wasserman, A.I. Software engineering issues for mobile application development. In Proceedings of the FSE/SDP Workshop on Future of Software Engineering Research-FoSER, Santa Fe, NM, USA, 7-8 November 2010.

21. Pandey, M.; Litoriya, R.; Pandey, P. Mobile APP development based on agility function. Ingénierie des Systèmes d'Information 2018, 23, 19-44. [CrossRef]

22. Joorabchi, M.E.; Mesbah, A.; Kruchten, P. Real challenges in mobile app development. In Proceedings of the 2013 ACM/IEEE International Symposium on Empirical Software Engineering and Measurement, Baltimore, MD, USA, 10-11 October 2013; pp. 15-24.

23. Punchoojit, L.; Hongwarittorrn, N. Usability Studies on Mobile User Interface Design Patterns: A Systematic Literature Review. Adv. Hum.-Comput. Interact. 2017, 1-22. [CrossRef]

24. Hardy, R.; Rukzio, E. Touch \& interact: Touch-based interaction of mobile phones with displays. In Proceedings of the 10th International Conference on Human Computer Interaction with Mobile Devices and Services, Amsterdam, the Netherlands, 2-5 September 2008; pp. 245-254.

25. Banga, C.; Weinhold, J. Essential Mobile Interaction Design: Perfecting Interface Design in Mobile Apps; Pearson Education: London, UK, 2014; pp. 39-57.

26. Huang, Q. Programming of Mobile GIS Applications. In The Geographic Information Science E Technology Body of Knowledge, 1st Quarter 2020 ed.; Wilson, J.P., Ed.; UCGIS: Washington, DC, USA, 2019. [CrossRef]

27. Lee, S.; Suh, J. Choi, Y. Review of smartphone applications for geoscience: Current status, limitations, and future perspectives. Earth Sci. Inform. 2018, 11, 463-486. [CrossRef]

28. Novakova, L.; Pavlis, T.L. Modern methods in structural geology of twenty-first century: Digital mapping and digital devices for the field geology. In Teaching Methodologies in Structural Geology and Tectonics; Mukherjee, S., Ed.; Springer Geology: Singapore, 2019; pp. 43-54.

29. Novakova, L.; Pavlis, T.L. Assessment of the precision of smart phones and tablets for measurement of planar orientations: A case study. J. Struct. Geol 2017, 97, 93-103. [CrossRef] 